\title{
ANALISIS PENERAPAN PRINSIP-PRINSIP ETIKA BISNIS ISLAM PADA PEDAGANG DI PD PASAR TRADISIONAL PANCASILA TASIKMALAYA
}

\author{
Nine Haryanti ${ }^{1}$, Trisna Wijaya ${ }^{2}$ \\ ${ }^{1}$ Program Studi Ekonomi Syariah, UIN Bandung, nineharyanti@gmail.com \\ ${ }^{2}$ Program Studi Ekonomi Syariah, Universitas Siliwangi, trisnawijaya @unsil.ac.id
}

\begin{abstract}
The concrete market is a gathering place for buyers and sellers to trade goods that are there. Based on preliminary studies indicated there are some traders who make a deviation in business practices in terms of Islamic business ethics principles. The formulation of this research is about how the application of Islamic business ethics principles to traders in traditional markets Pancasila Tasikmalaya. The purpose of this study is to find out how the application of Islamic business markets Pancasila Tasikmalaya. The research method using the descriptive method of the qualitative. The data source in this study, namely the primary data is interviewed to the relevant parties is traders, buyers and managers of traditional markets Pancasila. While the secondary data are data obtained through reports on traders and PD. Profiles the traditional market of Pancasila. By using data collection techniques in the form of observation, interview, and documentation. While the data analysis techniques using analytical techniques developed by Miles and Huberman, with its stages: data reduction, display data, and conclusion drawing/verification. Based on the results obtained from traders, buyers, and managers of traditional markets Pancasila shows that the principles of Islamic business ethics basically traders have applied in the activity of buying and selling. However, there are some deviations committed by traders in buying and selling such as, there are still those who neglect prayers, cheating on scales, selling goods below market prices due to tight market prices, less honest traders do not pay the debt to the supplier, doing savings and loan to conventional bank, unclear expiration limits, and there are still processed food products that add formalin and borax.
\end{abstract}

Keywords: Principles of Islamic Business Ethics.

\begin{abstract}
ABSTRAK
Pasar konkrit adalah tempat berkumpulnya pembeli dan penjual untuk memperjualbelikan barang-barang yang terdapat disana. Berdasarkan studi pendahuluan terindikasi ada beberapa pedagang yang melakukan penyimpangan dalam praktik bisnisnya ditinjau dari prinsip etika bisnis Islam. Rumusan penelitian ini adalah bagaimana penerapan prinsip-prisnip etika bisnis Islam pada pedagang di pasar tradisional Pancasila Tasikmalaya.
\end{abstract}


Tujuan penelitian ini adalah untuk mengetahui bagaimana penerapan prisnip-prinsip etika bisnis Islam pada pedagang di pasar tradisional Pancasila Tasikmalaya. Metode penelitian ini menggunakan metode deskriptif kualitatif. Adapun sumber data dalam penelitian ini, yaitu data primernya adalah wawancara pada kepada pihak-pihak yang terkait yaitu pedagang, pembeli dan pengelola pasar tradisional Pancasila, sedangkan data sekundernya adalah data-data yang diperoleh melalui laporan-laporan mengenai pedagang dan profil PD. Pasar tradisional Pancasila. Dengan menggunakan teknik pengumpulan data berupa observasi, wawancara, dan dokumentasi. Sedangkan teknik analisa data menggunakan teknik analisis yang dikembangkan oleh Miles dan Huberman, dengan tahapannya: reduksi data, penyajian data, dan penarikan kesimpulan. Berdasarkan hasil penelitian yang diperoleh dari para pedagang, pembeli dan pengelola pasar tradisional Pancasila menunjukan bahwa prinsip-prinsip etika bisnis Islam belum sepenuhnya diterapkan oleh para pedagang.

Kata Kunci: Prinsip, Etika Bisnis Islam.

\section{PENDAHULUAN}

Pasar merupakan sarana yang mendorong dan memperlancar kegiatan ekonomi masyarakat. Secara konkrit, pasar merupakan tempat bertemunya antara penjual dan pembeli, sehingga terjadi transaksi atau akad antara kedua belah pihak tersebut. Berdasarkan perkembangannya, pasar bisa dibagi menjadi pasar tradisional dan pasar modern. Pasar tradisional biasanya menampung pedagang kategori kecil dan menengah yang terlaksana tanpa teknologi yang modern. Sedangkan pasar modern adalah pasar yang menggunakan teknologi modern, konsumen dan pedagangnya dari golongan menengah ke atas dan harga yang ditawarkan bersifat tetap.

Salah satu permasalahan yang terjadi di pasar diantaranya adalah banyaknya praktikpraktik yang tidak sesuai dengan ajaran Islam, seperti kecurangan, penipuan, riba, sumpah palsu dan lain-lain. Perbuatan tersebut bisa disebabkan karena dorongan hawa nafsu atau tidak memiliki pengetahuan mengenai prinsip-prinsip etika bisnis Islam dalam melaksanakan kegiatan perdagangannya. Oleh karena itu pasar merupakan tempat yang paling dibenci oleh Allah swt sebagaimana sabda Rasulullah saw : "Tempat yang paling disukai Allah adalah masjid-masjidnya, dan tempat yang paling dibenci Allah adalah pasar”. (HR Muslim dari Abu Hurairah) (Al-Mundziri, 2013 : 104).

Pasar Pancasila merupakan salah satu pasar tradisional yang ada di Kota Tasikmalaya. Berdasarkan wawancara dengan pihak PD. Pasar Tradisional Pancasila Resik Kota Tasikmalaya, dalam kegiatan perdagangannya, masih ada para pedagang yang melakukan penyimpangan etika-etika bisnis Islam, seperti penipuan, kecurangan dalam timbangan, penggunaan bahan formalin dalam makanan, pengoplosan barang layak jual dengan barang yang tidak layak jual dan pelanggaran terhadap aturan pemerintah yang berpotensi merugikan konsumen. Di sisi lain pihak PD Pasar turun ke lapangan secara berkala untuk melakukan pemeriksaan dan pengawasan kepada para pedagang. 
Berdasarkan hasil wawancara dengan Bapak Yuyus (salah satu pengelola PD Pasar Tradisional Pancasila Resik Tasikmalaya), masih ada para pedagang yang mempraktikan riba seperti peminjaman uang ke rentenir dan lembaga keuangan konvensional dan praktik gharar (ketidak pastian) dalam transaksi jual beli, utang piutang dan sewa menyewa.

Kegiatan jual beli merupakan salah satu kegiatan bisnis yang bertujuan untuk mendapatkan keuntungan. Namun yang disayangkan, sebagian para pedagang kurang memperhatikan etika berbisnis dan mengabaikan aturan-aturan yang sudah ditetapkan. Mereka beranggapan bahwa dalam bisnis apapun boleh dilakukan selama hal itu mendatangkan keuntungan. Bagi sebagian para pedagang, pahala dan dosa hanya ada dalam kegiatan ibadah mahdhoh saja, dan tidak ada sangkut pautnya dengan dunia bisnis. Pemahaman yang seperti demikian sudah tentu tidak sejalan dengan prinsip-prinsip etika bisnis dalam Islam. Ironisnya, berdasarkan observasi peneliti, mayoritas para pedagang di pasar tradisional Pancasila adalah muslim, yang idealnya memegang prinsip-prinsip etika bisnis yang Islami.

Fenomena yang terjadi di pasar tradisional Pancasila tersebut sudah tentu memunculkan permasalahan. Oleh karena itu, penulis tertarik untuk melakukan penelitian dengan judul “Analisis Penerapan Prinsip-prinsip Etika Bisnis Islam pada Pedagang di Pasar Tradisional Pancasila Tasikmalaya".

\section{LITERATUR REVIEW}

\section{Etika Bisnis Islam}

Secara etimologi, etika berasal dari Bahasa Yunani yaitu "ethos" yang berarti: adat, akhlak, watak, perasaan, sikap, dan cara berpikir atau berarti adat istiadat. Bisa diartikan juga bahwa etika adalah "filsafat tentang nilai-nilai, kesusilaan tentang baik dan buruk". (Sumarni dan Johan, 2014 : 23). Dalam al-Qur'an, istilah yang paling dekat dengan istilah etika adalah khuluq. Untuk menggambarkan konsep kebaikan, al-Qur'an juga menggunakan istilah lain seperti khair, birr (kebenaran), qist (kesamaan), 'adl (keadilan), haqq (kebenaran dan kebaikan), ma'ruf(mengetahui dan menyetujui) dan taqwa (ketakwaan). Tindakan yang terpuji disebut shalihat dan tindakan yang tercela disebut sayyiat (Rivai dkk, $2012: 3$ ).

Husein Umar dalam bukunya mendefinisikan bisnis yaitu "seluruh kegiatan yang diorganisasikan oleh orang-orang yang berkecimpung di dalam bidang perniagaan (produsen, pedagang, dan industri dimana perusahaan berada) dalam rangka memperbaiki standar serta kualitas hidup mereka." (Husein Umar, 2001 : 4). Pada praktiknya, bisnis memiliki hubungan yang erat dengan etika, karena bisnis adalah aktivitas yang memerlukan tanggung jawab moral pada pelaksanaannya (Sunyoto, 2016 : 13-14).

Faisal Badroen menuliskan dalam bukunya bahwa "Etika Bisnis adalah aspek baik/ buruk, terpuji/ tercela, benar/ salah, wajar/ tidak wajar, pantas/ tidak pantas dari perilaku manusia ditambah dengan halal-haram atau sejumlah perilaku etis bisnis (akhlaq al Islamiyah) yang dibungkus dengan batasan syariah" (Faisal Badroen, $2006: 5$ ).

Etika Bisnis Islam adalah menyangkut "business firm" dan atau "business person", yang menyangkut arti yang bervariasi. Berbisnis berarti suatu usaha yang menguntungkan. Jadi etika 
bisnis Islami adalah studi tentang seseorang atau organisasi melakukan usaha atau kontak bisnis yang saling menguntungkan sesuai dengan nilai-nilai ajaran Islam. (Abdul Aziz, 2013 : 101).

\section{Urgensi Etika Bisnis Islam}

Urgensi etika dalam bisnis syariah, dapat ditinjau dari berbagai aspek, yaitu (Mardani, $2014: 30-31)$ :

1. Aspek teologis, bahwa etika bisnis dalam Islam merupakan ajaran Allah swt yang diwahyukan kepada Rasulullah saw, yang bersumber dari al-Qur'an maupun Sunnah.

2. Aspek watak manusia yang ingin cenderung mendahulukan keinginan dari pada kebutuhan. Oleh karena itu, jika mereka tidak memiliki etika dalam melaksanakan aktivitas bisnisnya, maka ada kecenderungan mereka akan melanggar aturan-aturan yang telah ditetapkan Allah swt dan Rasulullah saw.

3. Aspek sosiologis (reality), pada kenyataannya, watak dasar atau perilaku manusia yang cenderung amoral akan menciptakan persaingan yang tidak sehat. Etika diperlukan dalam segala aktivitas bisnis, agar mereka memahami dan menyadari mana aktivitas yang boleh dilakukan dan yang harus dihindari. Sehingga pebisnis tidak melakukan pelanggaran-pelanggaran dalam melakukan aktivitas bisnisnya.

4. Aspek perkembangan teknologi yang semakin pesat. Teknologi yang semakin canggih di satu sisi dapat mendatangkan nilai positif, yaitu bisa mempermudah dan mempercepat pemenuhan kebutuhan hidup manusia. Namun di sisi lain, teknologi canggih pun memiliki dampak negatif. Oleh karena itu etika bisnis Islami harus senantiasa diterapkan oleh para pebisnis dengan harapan mereka meninggalkan dan menghindari aspek negatif teknologi canggih.

5. Aspek akademis. Sehubungan dengan pentingnya etika bisnis, maka sudah sepantasnya kajian etika bisnis dijadikan sebagai salah satu kajian dalam dunia akademis.

\section{Prinsip-prinsip Etika Bisnis Islam}

Prinsip-prinsip dalam menjalankan bisnis (Faisal Badroen, 2006 : 89-101):

1. Unity (Tauhid)

Konsep tauhid (dimensi vertikal) berarti Allah swt telah menetapkan batas-batas tertentu atas perilaku manusia sebagai khalifah, untuk memberikan manfaat pada individu tanpa mengorbankan hak-hak individu lainnya, dan hubungan horizontal dengan kehidupan sesama manusia dan alam secara keseluruhan untuk menuju tujuan akhir yang sama.

\section{Equilibrium (Keseimbangan)}

Perilaku yang adil akan mendekatkan diri kepada ketakwaan, karena itu dalam bisnis, Islam melarang menipu, walaupun hanya sekedar membawa sesuatu pada kondisi yang menimbulkan keraguan sekalipun. Kondisi ini dapat memberikan gangguan pada mekanisme pasar atau adanya informasi penting mengenai transaksi yang tidak diketahui 
oleh salah satu pihak. Islam mengajarkan agar penganutnya berlaku adil dan senantiasa berbuat kebajikan.

\section{Free will (Kehendak bebas)}

Kebebasan merupakan hal yang penting dalam etika bisnis Islam, akan tetapi jangan sampai kebebasan ini mengganggu atau merugikan kepentingan bersama atau orang lain. Islam membolehkan umatnya untuk berinovasi dalam muamalah khususnya dalam kegiatan bisnis, akan tetapi Islam tidak memperbolehkan umatnya untuk melakukan hal-hal yang diharamkan oleh dalil.

\section{Responsibility (Tanggung jawab)}

Penerimaan pada prinsip tanggung jawab individu ini berarti setiap orang akan diadili secara personal di hari kiamat kelak. Tidak ada satu cara pun bagi seseorang untuk melenyapkan perbuatan-perbuatan jahatnya kecuali dengan memohon ampunan Allah dan melakukan perbuatan-perbuatan yang baik.

5. Benevolence (Ihsan)

Ihsan artinya melaksanakan perbuatan baik yang dapat memberikan kemanfaatan kepada orang lain, tanpa adanya kewajiban tertentu yang mengharuskan perbuatan tersebut atau beribadah dan berbuat baik seakan-akan melihat Allah, jika tidak mampu, maka yakinlah Allah melihat.

\section{METODE}

Dalam penelitian ini, peneliti menggunakan metode deskriptif, dengan pendekatan kualitatif. Pendekatan kualitatif adalah "suatu mekanisme kerja penelitian yang mengandalkan uraian deskriprif kata atau kalimat, yang disusun secara cermat dan sistematis mulai dari menghimpun data hingga menafsirkan dan melaporkan hasil penelitian." (Ibrahim, 2015 : 52). Metode deskriptif adalah "cara kerja penelitian yang dimaksudkan untuk menggambarkan, melukiskan, atau memaparkan keadaan suatu objek (realitas atau fenomena) secara apa adanya, sesuai dengam situasi dan kondisi pada saat penelitian dilakukan.” (Ibrahim, 2015 : 59)

Adapun sumber data dalam penelitian ini, yaitu data primernya adalah wawancara pada kepada pihak-pihak yang terkait yaitu pedagang, pembeli dan pengelola pasar tradisional Pancasila, sedangkan data sekundernya adalah data-data yang diperoleh melalui laporanlaporan mengenai pedagang dan profil PD. Pasar tradisional Pancasila. Teknik pengumpulan data yang digunakan dalam penelitian ini adalah observasi, wawancara, dan dokumentasi. Sedangkan teknik analisa data yang digunakan dalam penelitian ini adalah teknik analisis yang dikembangkan oleh Miles dan Huberman, dengan tahapannya: reduksi data, penyajian data, dan penarikan kesimpulan. (Sugiyono, 2012 : 373)

\section{HASIL DAN PEMBAHASAN}

Dalam penelitian ini, peneliti mewawancarai 4 orang pedagang, 4 orang konsumen dan 3 orang pengelola pasar tradisional Pancasila sebagai narasumber. Berdasarkan wawancara tersebut, bisa diketahui bagaimana penerapan prinsip etika bisnis Islam yang terdiri dari unity 
(tauhid), equilibrium (keseimbangan), free will (kehendak bebas), responsibility (tanggung jawab) dan benevolence (ihsan).

1. Unity (Tauhid)

Prinsip kesatuan yang disebut juga dengan tauhid merupakan etika yang sangat penting dalam melakukan transaksi bisnis khususnya jual beli. Implementasi prinsip tauhid dalam berbisnis yaitu dengan melaksanakan perintah Allah swt dan menjauhi larangan-Nya dalam kegiatan berbisnis seperti jual beli. Misalnya tidak melakukan praktik gharar, riba, menjaga ibadah mahdhah-nya seperti menjaga shalat lima waktu, melaksanakan ibadah puasa, menunaikan zakat, sedekah dan lain sebagainya.

Dari segi ketauhidan, pedagang yang beragama Islam merasa yakin bahwa segala sesuatu yang terjadi merupakan kehendak Allah swt. Mereka juga meyakini bahwa rezeki yang diterimanya adalah pemberian Allah swt. Dengan demikian, mereka memberikan sebagian hartanya untuk membayar zakat dan sedekah atas kesadaran masing-masing dan tanpa paksaan dari pihak lain sebagai bentuk ketaatan kepada Allah swt. Mereka mengetahui bahwa membayar zakat merupakan salah satu perintah Allah swt sebagaimana difirmankan :

"Ambillah sedekah (zakat) dari sebagian harta mereka, dengan zakat itu kamu membersihkan dan mensucikan mereka dan berdoalah untuk mereka. Sesungguhnya doa kamu itu (menjadi) ketentraman jiwa bagi mereka. Dan Allah maha mendengar lagi maha mengetahui." (QS. At-Taubah : 103)

Berdasarkan hasil observasi, para pedagang di pasar tradisional Pancasila bisa dibilang lalai dalam menjalankan kewajibannya Dalam pelaksanaan shalat wajib, belum semua pedagang melaksanakan shalat wajib tepat waktu atau diawal waktu. Dengan alasan melayani pembeli terlebih dahulu, dan ada juga yang melaksanakan shalat secara bergantian dengan partner kerjanya. Bahkan pada hari jumat pun, masih ada pedagang laki-laki dewasa yang tidak melaksanakan shalat jumat. Dengan demikian bisa disimpulkan bahwa pedagang belum sepenuhnya mengimplementasikan prinsip tauhid dalam kegiatan bisnisnya.

2. Equilibrium (Keseimbangan/ Keadilan)

Berdasarkan pengamatan peneliti, para pedagang di Pasar tradisional Pancasila belum sepenuhnya mengimplementasikan prinsip keseimbangan atau keadilan. Itu dikarenakan masih ada pedagang yang sengaja mengurangi timbangan demi mengambil keuntungan yang lebih banyak. Berdasarkan infomasi dari pengelola PD Pasar Tradisional Pancasila, pernah terjadi ketidak sesuaian timbangan setelah dilakukan pengecekan timbangan dengan alat tera ulang (alat ukur). Sudah tentu hal ini dapat merugikan pihak konsumen atau pembeli.

Tindakan mengurangi takaran merupakan sama saja dengan penipuan dan kecurangan. Perilaku keadilan dalam berbisnis secara tegas dijelaskan dalam konteks agar pengusaha muslim menyempurnakan takaran bila menakar dan menimbang dengan neraca yang benar, karena itu merupakan perilaku yang terbaik dan membawa akibat 
yang terbaik pula (www.eprints.walisongo.ac.id). Dengan menerapkan prinsip keadilan, diharapkan hak-hak konsumen atau pembeli dapat terpenuhi.

3. Free Will (Kehendak Bebas)

Prinsip kebebasan merupakan bagian penting dalam etika bisnis Islam, namun bukan berarti bebas melakukan hal yang bisa merugikan kepentingan umum. Pada prinsip kehendak bebas, para pedagang memberikan kebebasan bagi pedagang lain untuk berjualan di dekatnya dan memberikan kebebasan bagi pedagang untuk menetapkan harga barang jualannya, apakah itu lebih mahal dari harga pasar atau lebih murah. Namun bagi pedagang yang menetapkan harga barangnya lebih mahal dari harga pasar memiliki risiko dagangannya tidak laku, yang menyebabkan kiosnya sepi dan tidak bertahan lama. Namun dalam Islam terdapat larangan membanting harga sehingga bisa menjatuhkan harga pasar.

Harga-harga barang yang dijual di pasar Pancasila memang lebih mahal dibandingkan dengan pasar Cikurubuk, karena kebanyakan barang yang dijual oleh pedagang di pasar Pancasila berasal dari pasar Cikurubuk. Namun sebagian pedagang menjual barang dagangannya dengan harga yang lebih murah, karena mereka membeli barang tersebut langsung dari supplier atau petani (bagi pedagang sayuran).

Dalam transaksi jual beli, para pedagang memberikan kesempatan bagi konsumen untuk menawar harga barang jika harganya dianggap tidak sesuai atau terlalu mahal, akan tetapi para pedagang juga memiliki standar harga sendiri.

Dalam kegiatan jual beli, tidak ada pedagang yang melakukan praktik riba dalam transaksi jual belinya. Namun praktik riba ini ditemukan dalam transaksi pinjaman uang kepada rentenir dan lembaga keuangan konvensional.

Prinsip kehendak bebas memang belum diterapkan oleh sebagian para pedagang di pasar Pancasila. Dikarenakan ada pedagang yang melakukan tindakan yang tidak sesuai dengan prinsip tersebut seperti menjual barang di bawah harga pasar, peminjaman uang kepada rentenir atau lembaga keuangan konvensional dan pencampuran bahan makanan dengan bahan pengawet seperti borax dan formalin, yang berpotensi merugikan konsumen.

4. Responsibility (Tanggung jawab)

Berdasarkan hasil penelitian, para pedagang belum sepenuhnya menjalankan prinsip tanggung jawab, masih ada pedagang yang melaksanakan aktivitas jual beli yang tidak sesuai dengan syariat Islam, seperti tidak menyembunyikan kekurangan atau kecacatan barang, tidak membayar hutang kepada distributor atau suplier dan pelanggaran akad sewa menyewa ruko atau lapak dengan pihak pengelola pasar.

5. Benevolence (Ihsan)

Prinsip ihsan atau kebajikan berkaitan dengan sikap pedagang dalam melayani dan memperlakukan konsumen. Sikap sopan, ramah, murah hati dan sabar yang dimiliki dan diperlihatkan pedagang kepada para konsumen atau pembeli akan menjadi daya tarik tersendiri dan akan memberikan kesan positif. Sebaliknya sikap tidak ramah, tidak 
sopan, tidak sabar dan membedakan perlakuan kepada konsumen yang berbeda yang diperlihatkan pedagang akan memberikan kesan negatif bagi para pedagang. Dalam aktivitas jual belinya, para pedagang di pasar Pancasila belum semua menerapkan prinsip ihsan. Masih ada pedagang yang menunjukan perlakuan yang berbeda kepada konsumen-konsumennya dan ada juga sebagian pedagang yang menunjukan sikap kurang ramah kepada para konsumennya.

\section{KESIMPULAN}

Berdasarkan hasil penelitian wawancara dan observasi yang diperoleh dari pedagang, pembeli dan pengelola PD. Pasar Tradisional Pancasila Tasikmalaya menunjukkan bahwa prinsip-prinsip etika bisnis Islam belum sepenuhnya di terapkan dalam aktivitas jual belinya. Masih ada beberapa penyimpangan yang dilakukan oleh pedagang dalam aktivitas jual beli seperti melalaikan shalat, kecurangan dalam timbangan, menjual barang dibawah harga pasar karena ketatnya harga pasar, pedagang kurang jujur tidak membayar hutang ke suplier, melakukan simpan pinjam ke bank konvensional, batas kadaluarsa yang tidak jelas, sikap kurang ramah pedagang dan perlakuan berbeda (diskriminatif) terhadap konsumen yang ditunjukan pedagang dan masih terdapat produk olahan makanan yang menambahkan formalin dan borax.

\section{REFERENSI}

Al-Mundziri, Imam. (2013). Ringkasan Shahih Muslim. Bandung: Jabal.

Sumarni, M. dan Suprihanto, J. (2014). Pengantar Bisnis (Dasar-Dasar Ekonomi Perusahaan. Yogyakarta: Liberty Yogyakarta.

Umar, Husein. (2001). Studi Kelayakan Bisnis. Jakarta : Gramedia Pustaka Utama

Badroen, Faisal. (2006). Etika Bisnis dalam Islam. Jakarta : Prenada Media Group

Aziz, Abdul. (2013). Etika Bisnis Perspektif Islam (Implementasi Etika Islami untuk Dunia Usaha. Bandung : Alfabeta

Mardani. (2014). Hukum Bisnis Syariah. Jakarta : Prenadamedia Group

Ibrahim. (2015). Metode Penelitian Kualitatif. Bandung : Alfabeta

Sugiyono. (2012). Metode Penelitian Pendidikan Pendekatan Kuantitatif Kualitatif dan R\&D. Bandung : Alfabeta)

Rivai, Veithzal, dkk. (2012). Islamic Business and Economic Ethics. Jakarta : Bumi Aksara 